\title{
Aprendizagem e fatores motivacionais relacionados
}

\author{
Arnaldo Nogaro* \\ Idanir Ecco* \\ Luciane F. R. Rigo ${ }^{* * *}$
}

\section{Resumo}

Este texto resulta de pesquisa bibliográfica, exploratória, de caráter qualitativo, parte do trabalho de conclusão de pós-graduação, para a qual se utilizou como fontes básicas obras e artigos de autores reconhecidos. O objetivo proposto é demonstrar a importância da motivação no espaço escolar, como ela contribui, interfere nos processos educativos, no ambiente escolar, na aquisição do conhecimento, em síntese, no trabalho do professor, no ensino e na aprendizagem. A arquitetura do texto está estruturada de modo a conceituar motivação e aprendizagem e, posteriormente, relacioná-los com os fatores motivacionais interferentes na aprendizagem e na melhoria da qualidade do ensino. Conclui-se, demonstrando que a motivação é discurso recorrente nos espaços escolares, no entanto, longo caminho a percorrer no que diz respeito a constituir-se em ações objetivas para sua incorporação na prática pedagógica. O que se evidencia são atitudes reveladoras de ausência de motivação para o aprendizado e para o trabalho escolar. Os educadores têm noções elementares a respeito de sua importância no processo educativo, mas falta-lhes conhecimento aprofundado para inseri-las na prática cotidiana e em como fazer uso dos fatores motivacionais no sentido de melhorar as relações com os estudantes e sua aquisição de conhecimento.

Palavras-chave: Motivação. Aprendizagem. Professor. Estudante.

Recebido: 20/01/2014 - Aprovado: 12/04/2014

http://dx.doi.org/10.5335/rep.v21i2.4309

Doutor em Educação pela Universidade Federal do Rio Grande do Sul. Professor da Universidade Regional Integrada - Campus Erechim. E-mail: narnaldo@uri.com.br.

** Mestre em Educação pela Universidade de Passo Fundo. Professor da Universidade Regional Integrada - Campus Erechim. E-mail: idanir@uri.com.br.

*** Licenciada em Química. Especialista em Psicopedagogia pela Universidade Regional Integrada - Campus Erechim. Professora da Rede Particular de Ensino de Erechim. E-mail: lucarohr@yahoo.com.br. 


\section{Introdução}

A motivação é um problema de pontual na educação, a qual afeta diretamente os envolvidos no processo de ensino e de aprendizagem. Segundo a visão de Marchesi (2006), a motivação para aprender configura-se como o centro da reflexão na área de educação, e sua ausência, o principal fator do fracasso escolar, ou seja: motivar o estudante constitui-se em uma tarefa constante de quem ensina, que, também, precisa estar motivado para desenvolver seu trabalho. Por essa razão, a motivação pode ser considerada como um determinante do êxito escolar. Cientes de sua importância, temos como objetivo para esta pesquisa, demonstrar como a motivação (fatores motivacionais) contribui/interfere nos processos de aprendizagem e na aquisição do conhecimento.

A motivação ou ausência desta, não é um tema exclusivo da área da educação, tem sido estudada e abordada em outros campos do conhecimento como na Psicologia, na Administração e no Esporte, dentre outros. Aqui se objetiva tratar de sua relação com a aprendizagem escolar. Muitos são os profissionais que se deparam com dificuldades em proporcionar aulas atraentes e estimulantes, fazendo com que os alunos interajam de maneira mais dinâmica e que a aprendizagem possa efetivar-se naturalmente. Para que isso ocorra faz-se necessário que professores compreendam qual a importância e qual o papel da motivação no processo educativo e na aquisição de conhecimento.

A matéria-prima do trabalho do professor são os processos de aprendizagem, uma vez que trabalha com mudança de comportamento, atitudes e aquisição de saber. Precisa-se ter clareza a respeito do que é e de como ocorre a aprendizagem, quais fatores/elementos internos e externos auxiliam o indivíduo para que essa se realize de maneira exitosa, e qual a contribuição da motivação para que seja bem-sucedida.

A reflexão referente à motivação, à aprendizagem, ao conhecimento suscita dúvidas e provoca interrogações, cujas origens podem ser identificadas entre pais, educadores e até entre estudantes. $\mathrm{O}$ que queremos dizer quando falamos em motivar alguém? É possível motivar um indivíduo? Quais estratégias utilizar? Os fatores imbricados na motivação são de natureza intrínseca ou extrínseca ao sujeito? Quem deve ser responsabilizado pela desmotivação do estudante? O que os professores conhecem em relação à motivação para a aprendizagem?

Há uma constatação cotidiana, muito recorrente, no que diz respeito à dificuldade encontrada por professores em trabalhar com estudantes poucos motivados, constituindo-se um dos grandes entraves do trabalho do professor. Como mudar este panorama? Quais atitudes tomar para encontrar saídas para esse problema? O ponto de partida pode ser o esclarecimento dos professores em relação à importân- 
cia da motivação, bem como a identificação de quais são os fatores que contribuem, de maneira significativa ou não, para com o processo motivacional. No momento em que os professores souberem ou tiverem o conhecimento da interferência da motivação, poderão planejar e estruturar suas aulas de forma a tornarem-se mais atrativas e estimulantes, ao mesmo tempo, em que poderão utilizar mecanismos que oportunizem melhor aprendizado. O que se evidencia é que os docentes percebem a falta de motivação, mas conhecem pouco dessa e como agir para que se faça presente no processo educativo. Observa-se que os estudantes gostam e sentem-se motivados para ir à escola, para frequentar o ambiente escolar, no entanto, não se sentem atraídos para o trabalho de aprender e de adquirir o conhecimento da sala de aula. $\mathrm{O}$ aprender é um processo exigente que envolve esforço e muito trabalho, cujo êxito está vinculado à quantidade de energia e envolvimento dispensados pelos estudantes e por seus professores.

Pouco importa as razões de ordem pessoal expressas em relação à aprendizagem, o que mais chama a atenção é a ausência de preocupação, de envolvimento ao entrar em uma sala de aula, tanto por parte do professor, quanto do aluno. Pensamos que todo esse contexto de ausência de motivação reflete-se em aulas monótonas, sem interação e com o ser humano concebido compartimentado (sem visão de complexidade e de interdisciplinaridade), sem a unidade que o torna pleno e que é matriz da aprendizagem, pois esta é um fenômeno existencial, cujo ponto de partida "[...] é a pessoa inteira - ou seja, corpo e mente" (JARVIS, 2013, p. 42). De maneira geral, vislumbram-se aulas com métodos conservadores, nas quais predomina a exposição do professor e o estudante ouvindo, ou, por vezes desatento, em atitude que demonstra descaso. Acreditamos que essa realidade está deixando à sociedade, ao mundo, pessoas apáticas, submissas e pouco comprometidas.

A partir de certas reflexões, chegamos à conclusão de que um percentual expressivo de educadores está alheio a essa questão, e pior, não sabem o real significado e importância de planejar e praticar aulas em que ocorra uma aprendizagem significativa. Essa vincula-se aos fatores motivacionais, pois para motivar o estudante o educador precisa ser atencioso, dinâmico e sanar/clarear dúvidas que surgirem no decorrer da aula, como também envolve um planejamento bem estruturado, essencial para a boa prática educativa. Nessa direção, o texto que segue constitui-se em uma produção teórica resultante de pesquisa bibliográfica, de caráter qualitativo, em obras e autores contemporâneos, dentre os quais estão Pozo (2002), Galand e Bourgeois (2011), Marchesi (2006), Burochovitch (2004; 2010). Estes visam problematizar e trazer conhecimentos que possam contribuir com o debate desse tema. Para isso, apresentamos ideias relacionadas à motivação e à aprendizagem e como os fatores motivacionais interferem no processo de mobilização dos sujeitos e na aquisição de conhecimento. 


\section{Aprendizagem: um conceito plural e complexo}

A aprendizagem é o processo pelo qual as competências, as habilidades, os conhecimentos, os comportamentos ou os valores são adquiridos ou modificados, como resultado de estudo, experiência, formação, raciocínio e observação. "Quando elaboramos os nossos próprios conceitos e, consequentemente, nossas opiniões, percebemos que transformamos as informações em conhecimentos. $\mathrm{E}$ isso acontece durante toda a nossa vida. Estamos constantemente aprendendo a fazer o uso de novos instrumentos [...]" (PORTILHO, 2009, p. 13).

Para Illeris (2013, p. 16), a aprendizagem caracteriza-se como "[...] qualquer processo que, em organismos vivos, leve a uma mudança permanente em capacidades e que não se deva unicamente ao amadurecimento biológico ou ao envelhecimento." O autor afirma também que a aprendizagem tornou-se um tema fundamental nas últimas duas décadas, mesmo fora do âmbito escolar, em razão de sua relação estratégica com a sociedade do conhecimento, constituindo-se, também, em uma questão bastante complexa, o que dificulta uma definição conceitual mais precisa. Por envolve um conjunto muito amplo e complicado de processos, induz estudiosos a uma diversidade de interpretações, refletindo-se em grande número de teorias a seu respeito. Ideia essa que é partilhada por Pozo (2002) ao expressar que vivemos muitos contextos e situações, provocando uma diversidade de necessidades de aprendizagem, o que faz com que seja difícil tonar "[...] compatível com a ideia simplificadora de que uma teoria ou modelo de aprendizagem pode dar conta de todas essas situações" (POZO, 2002, p. 33).

A aprendizagem humana está relacionada à educação e ao desenvolvimento pessoal, pois requer envolvimento e iniciativa. Galand e Bourgeois (2011) confirmam isso dizendo que é um verdadeiro trabalho e, como tal, exige mobilização de recursos pessoais - cognitivos, afetivos, comportamentais - importantes, uma mobilização que requer, desde o início, um intenso envolvimento do sujeito na sua aprendizagem. Além disso, deve ser devidamente orientada e é favorecida quando o indivíduo está motivado. O estudo da aprendizagem utiliza os conhecimentos e as teorias da neuropsicologia, da psicologia, da educação e da pedagogia.

Não é só que tenhamos de aprender muitas coisas, temos que aprender muitas coisas diferentes. A diversidade de necessidades de aprendizagem é dificilmente compatível com a ideia simplificadora de que uma única teoria ou modelo de aprendizagem pode dar conta de todas essas situações (POZO, 2002, p. 33).

A aprendizagem é uma das funções mentais mais importantes em humanos e animais e, também, pode ser aplicada a sistemas artificiais. A função fundamental da aprendizagem humana é interiorizar ou incorporar a cultura, para assim 
fazer parte dessa (POZO, 2002). O estabelecimento de novas relações entre o ser e o meio ambiente tem sido objeto de vários estudos empíricos em animais e seres humanos. O processo de aprendizagem pode ser medido por meio das curvas de aprendizagem, ${ }^{1}$ as quais mostram a importância da repetição de certas predisposições fisiológicas, de "tentativa e erro" e de períodos de descanso, após o qual se pode acelerar o processo. Nessa perspectiva, de acordo com Marchesi (2006), a aprendizagem é, portanto, um processo dinâmico em que o aluno estabelece relações entre a informação disponível e constrói passo a passo, com avanços e retrocessos, uma espécie de modelo mental ou de representação interna que reflete o que aprendeu e que lhe serve para recuperar a informação já estruturada e para conectar a nova informação.

A aprendizagem se baseia na atividade mental da pessoa que aprende, que deve fazer um esforço para conectar o que sabe com a nova informação que recebe. Essa atividade mental supõe construção de significados por parte do aprendiz, que se baseiam no estabelecimento de conexões e relações entre os esquemas de conhecimento disponíveis e a nova informação (MARCHESI, 2006, p. 32).

Uma teoria de aprendizagem é, sempre, uma construção humana para interpretar sistematicamente a área de conhecimento que chamamos de aprendizagem. Representa, dessa forma, um ponto de vista de um autor/pesquisador a respeito de como interpretar o tema, tentando explicar o que é e porque funciona como funciona. "A pessoa quando aprende, precisa, também, desenvolver um conhecimento sobre si mesmo, assim como procurar quais os mecanismos que utiliza para aprender, o que já conhece e o que falta por conhecer, organizando assim seus conhecimentos dentro de uma visão global" (PORTILHO, 2009, p. 14).

Essas ideias não negam completamente as concepções antigas do aprendizado. É possível aprender recebendo informações, treinando e decorando regras. Mas, dessa maneira, a compreensão daquilo que se aprende costuma ser bem pequena.

Ressaltamos que a pessoa quando aprende precisa, também, desenvolver um conhecimento sobre si mesmo, assim como procurar saber quais os mecanismos que utiliza para aprender, o que é que já se conhece e o que falta por conhecer, organizando assim seus conhecimentos dentro de uma visão de globalidade (PORTILHO, 2009, p. 78).

E esta é a diferença: o que se procura por meio da Psicologia Cognitiva é favorecer o aprendizado com compreensão.

As pesquisas cognitivistas mostram que, ainda que os sujeitos tenham capacidades ou inteligências para aprender, é necessário que o ambiente brinde oportunidades ao desenvolvimento de tais capacidades e inteligências, chamando a atenção principalmente à relação pedagógica entre aluno e professor (PORTILHO, 2009, p. 17). 
Professores estudiosos e esclarecidos entendem, completamente, que o ensino e a aprendizagem bem-sucedidos acontecem quando há relacionamentos de cuidado e solidariedade com seus alunos e quando estes estão envolvidos emocionalmente com sua aprendizagem. A aprendizagem verdadeira supõe um professor que assuma, coordene e alimente o processo vivo do aluno. Este é o responsável pelos desafios que o aluno terá que enfrentar.

Assim, práticas formativas referem-se a maneiras bem identificáveis de ensinar, mas também à qualidade das relações entre professor e aluno, ao exemplo profissional, à autoridade intelectual do professor formador, entre muitas outras ocorrências que os alunos podem avaliar como importante para o aprendizado do ser professor (GUIMARÃES, 2004, p. 56).

A boa aprendizagem do aluno tem uma correlação muito estreita com a atuação do professor, o que faz Costa (2003) afirmar que o papel do educador é o de acompanhar o educando, ajudando a atualizar o seu potencial, respeitando sua história e deixando lugar para a criatividade, a afetividade e a emoção não assumir seu lugar. Resende (2008) sintetiza o que ocorre na aprendizagem quando afirma que não é o professor que faz a relação para o aluno, mas o próprio aluno, como sujeito da ação educativa e pelo significado que essa ação tenha para ele. $O$ trabalho pedagógico realizado pelo professor pode facilitar e/ou dificultar relações, mas não construí-las para outro sujeito.

\section{Motivação para a aprendizagem}

O dicionário Houaiss (2001) define motivação como o conjunto de fatores, os quais agem entre si, e determinam a conduta de um indivíduo. É acreditando nesse conjunto de fatores, que existe dentro de cada um de nós, que fazem com que determinemos nosso jeito de ser e estar na vida que conseguimos alcançar aquilo que desejamos. A palavra motivação deriva do latim motivus, movere, que significa deslocar-se, mover-se. Motivação é a força, o impulso que nos move e direciona o comportamento em busca da satisfação de uma determinada necessidade, por isso não podemos considerá-la como simples injeção de ânimo, que deve ser aplicada de vez em quando nos indivíduos, pois são as influências externas geradas, consciente ou inconscientemente, pelo próprio homem.

No ambiente escolar, a motivação é um dos fatores favoráveis ao aprendizado e sua falta deixa espaço para a passividade, para a indisciplina, além de dificultar o desenvolvimento das atividades e gerar desconcentração. "Em outras palavras haverá motivação por uma atividade se estiver bem claro para que executá-la e, portanto, a estratégia motivacional consistirá em mostrar esse valor instrumental, o que pode ser demonstrado de diversas maneiras" (BORUCHOVITCH, 2010b, 
p. 17). Marchesi (2006) identifica duas condições para se enfrentar uma tarefa de aprendizagem: a primeira é entendê-la, quer dizer, compreender em que consiste e o que se deve fazer para resolvê-la; a segunda é sentir-se capaz de realizá-la ou, pelo menos, de pôr em ação as estratégias disponíveis para consegui-lo. "Os alunos com escassa motivação para aprender não têm uma delas ou, em muitos casos, nenhuma delas" (MARCHESI, 2006, p. 64).

A palavra motivação é, atualmente, uma das mais usadas pelos professores e por outros responsáveis pela educação, em particular na educação formal, para justificar insucesso dos alunos. Muitos educadores colocam a alegada falta de motivação dos alunos como primeiro obstáculo à compreensão e aprendizagem dos conteúdos escolares. Curiosamente, grande parte das dificuldades do professor tem, também, origem na sua motivação para adquirir sólido conhecimento profissional, susceptível de ajudá-los na difícil tarefa de diagnosticar os interesses e as necessidades dos alunos e de perceber as diferenças individuais e outros problemas condicionantes de aprendizagem.

Esses alunos estão em uma situação paradoxal: aparentemente, dispõem de habilidades cognitivas que permitem vencer na escola, mas a imagem que têm da própria capacidade os leva a desanimar e a pôr obstáculos ao seu êxito escolar. Sua dificuldade é de natureza claramente motivacional, ao passo que as prevenções propostas focalizam, com frequência, o domínio das matérias escolares. Essas pesquisas convidam a lançar um outro olhar sobre os alunos desmotivados ou com dificuldade (GALAND; BOURGEOIS, 2011, p. 12).

A motivação é um estado interno, resultante de uma necessidade, que desperta certo comportamento, com o objetivo de suprir essa necessidade. Os usos que um indivíduo faz de suas capacidades humanas dependem da sua motivação - seus desejos, carências, ambições, apetites, amores, ódios e medos. As diferentes motivações e cognições de um sujeito explicam a diferença do desempenho de cada um. "Na verdade, a motivação não é uma variável unitária, mas um composto de várias dimensões, feito de sentimentos, apreciações individuais e de resultados de experiências anteriores" (GALAND; BOURGEOIS, 2001, p. 116).

$\mathrm{Na}$ sala de aula, a motivação constitui-se em geradora de energia positiva para que os estudantes realizem determinadas tarefas e alcancem os objetivos determinados/desejados. As atividades e propostas de trabalho devem ter características desafiadoras, para tirá-los da inércia e da posição cômoda de não se envolver.

[...] motivação é um produto da expectativa de sucesso pelo valor da meta proposta, há dois caminhos fundamentais através dos quais os professores podem incrementar a motivação dos alunos ou os alunos a sua própria: aumentando a expectativa de sucesso e / ou valor desse sucesso (POZO, 2002, p. 145). 
Motivar consiste em apresentar a alguém estímulos e incentivos que lhe favoreçam determinado tipo de conduta, ou seja, em sentido didático, consiste em despertar o interesse do aluno e envolvê-lo, de modo apropriado, para tornar a aprendizagem mais eficaz.

Galand e Bourgeois (2011) chamam atenção para o teor das relações, nas quais os estudantes estão envolvidos, que podem aproximá-los ou afastá-los da escola e do professor.

Dar aos alunos a impressão de que suas necessidades são ouvidas, de que são apoiados em seus esforços, instaurar na classe regras claras e, ao mesmo tempo, um ambiente de cooperação e ajuda mútua contribuirá para melhorar o bem-estar dos alunos, seu envolvimento na classe e sua motivação para o trabalho escolar e o estudo (GALAND; BOURGEOIS, 2011, p. 125).

O ambiente escolar e interno da sala de aula, a qualidade das relações intersubjetivas, o relacionamento entre diferentes atores que interagem, no espaço da escola e mesmo fora dela (professor-aluno, aluno-aluno, aluno-gestores, pais-filhos [...]), colocam-se como fatores motivacionais importantes para que o estudante encontre o equilíbrio e a segurança necessários para atingir a aprendizagem. Relações instáveis, conflituosas ou de submissão prejudicam e interferem, negativamente, na qualidade das aprendizagens.

\section{Fatores e caracterização de elementos que contribuem para a aprendizagem}

Dentre as preocupações que o educador deve ter ao elaborar uma situação de aprendizagem está a de criar condições favoráveis para que essa aconteça, de maneira natural e objetiva. Deve-se ter, também por base, duas premissas: o que vai ensinar (objetivos a serem alcançados) e como ensinar (estratégias a serem utilizadas). Para Bzuneck (2010), as influências da motivação dependem não apenas da simples declaração comunicada de acerto ou de erro, que seria um feedback bem sucinto, mas, sobretudo, do conteúdo das verbalizações complementares do professor em cada situação. Para motivar alguém não bastam técnicas, faz-se necessário trabalhar com elementos de ordem emocional, afetiva e relacional, dentre outros.

Illeris (2013) trata dos processos básicos que levam à aprendizagem, dizendo-nos que há três dimensões que fazem parte desse processo: o conteúdo, o incentivo e a interação. Segundo o autor, localiza a motivação, volição dentro da dimensão do incentivo que proporciona e direciona a energia mental necessária para o processo de aprendizagem. Sua função é "[...] garantir o equilíbrio mental contínuo do indivíduo e, assim, desenvolver simultaneamente uma sensibilidade pessoal" (ILLERIS, 2013, p. 18). Os incentivos não funcionam isolados, necessitam do conteúdo 
que vai mudando e provocando novo desejo, interesse. Assim, conteúdo e incentivo (motivação) atuam em sintonia para que o sujeito construa significado e desenvolva a capacidade de lidar com os desafios da vida prática. A dimensão da interação completa a tríade ao propiciar os impulsos que dão início ao processo ocorrido na percepção, na transmissão, na experiência e na atividade, dentre outras.

Para demonstrar como os fatores citados interferem na aprendizagem do estudante e no trabalho do professor, vale a pena reproduzir aqui o exemplo trazido por Illeris (2013, p. 20):

Durante uma aula de química na sala de aula, o professor está explicando um processo químico. Os alunos deveriam estar ouvindo e talvez fazendo perguntas para garantir que entenderam a explicação corretamente. Os estudantes, desse modo, são envolvidos em um processo de interação. Todavia, ao mesmo tempo, eles devem absorver ou aprender aquilo que o professor está ensinando, isto é, relacionar psicologicamente o que é ensinado com o que já devem ter aprendido. $O$ resultado deve ser que eles consigam lembrar aquilo que lhe ensinaram e, sob certas condições, reproduzir, aplicá-lo e envolvê-lo na nova aprendizagem.

Quando algum aspecto (referido na citação) envolvido falhar ou produzir erro (atenção do aluno, método do professor, relações conflituosas na sala de aula...) haverá prejuízo ou não ocorrerá a aprendizagem esperada. Estudos indicam “[...] que a qualidade das relações sociais com os outros alunos e com os professores pode influenciar de forma significativa o sucesso escolar" (GALAND; BOURGEOIS, 2011, p. 76). Portanto, a aquisição de conhecimento não é algo apenas cognitivo, aparecem diferentes interferentes, dentre os quais, Illeris destaca a importância dos relacionados ao incentivo.

Todavia, a função de incentivo também é crucial, isto é, como a situação é vivida, que tipos de sentimentos e motivações estão envolvidos e, assim, a natureza e intensidade de energia mental que é mobilizada. O valor e a durabilidade da aprendizagem resultante estão intimamente relacionados com a dimensão do incentivo ao processo de aprendizagem (2013, p. 20).

A importância de fazer com que o estudante possa viver e experimentar acontecimentos positivos em relação à sua aprendizagem é crucial, pois o cérebro está estruturado para localizar e comparar fatos e situações vividas com as propostas e, com base no êxito ou no fracasso, desejar viver ou bloquear a realização do proposto. Rey (2008) é enfático ao afirmar que as emoções que o sujeito desenvolve no processo de aprendizagem estão associadas não apenas ao que esse vivencia, como resultado das experiências implicadas no aprender, mas às emoções que têm sua origem "[...] em sentidos subjetivos muito diferentes que trazem ao momento atual do aprender momentos de subjetivação produzidos em outros espaços e momentos da vida" (REY, 2008, p. 34). 
Estudos apontam que estudantes com experiências escolares positivas tem cada vez melhor desempenho motivados pela compensação que seu cérebro espera ter ao realizar nova experiência, na qual acredita obter pleno êxito. Assim, um dos motivadores da aprendizagem está em oportunizar ao estudante situações que façam com que esse ressignifique e obtenha sucesso nas tarefas desde o início de sua escolaridade. $\mathrm{O}$ sentimento de fracasso gera bloqueios e desencoraja a realização de tais atividades, o que Illeris (2013) denomina de "resistência mental" à realização de uma tarefa ou de aprendizagem. Nesse contexto, não significa dizer que o sujeito não tenha capacidade de fazer, o que ocorre é que esse esforça-se em não realizar aquilo, podendo, em outra situação, aprender ou realizar atividades semelhantes, desde que deseje. Na ótica de Galand e Bourgeois (2011), ainda que o indivíduo esteja certo de poder realizar uma tarefa ou uma determinada atividade, esse pode não ter nenhuma razão para envolver-se.

Além de sentir-se capaz, o estudante precisa mobilizar seus desejos e suas vontades internas, levando-o a realizar ações e atividades que oportunizem o aprendizado. Segundo Meirieu (2005), supondo que todas as crianças do mundo possam beneficiar-se de uma adubagem educativa inicial idêntica e desenvolver o mesmo desejo de saber, isso não garantiria que essas chegassem ao desejo de aprender. É uma grande ingenuidade acreditar que, pelo fato de uma pessoa querer saber, esta queira também aprender.

Há vários fatores ou condições que concorrem para que ocorra a aprendizagem, os quais podem facilitar ou inibir o processo. Esses podem ser de ordem interna ou externa ao sujeito ou, se quisermos utilizar outras palavras, para entender melhor, o que ocorre como processo psicológico interno de elaboração e aquisição e o que ocorre pela interação entre o indivíduo e o seu ambiente. ${ }^{2}$ Illeris $(2013$, p. 27$)$ define as condições internas como "[...] as características do aprendiz que influenciam as possibilidades de aprendizagem e estão envolvidas nos processo referentes a eles" [e as condições externas como os] "[...] aspectos situados fora do indivíduo que influenciam as possibilidades e estão envolvidos nos processo de aprendizagem". ${ }^{3}$ Alguns desses fatores estão relacionados com características dos alunos a quem se destina a aprendizagem.

Neste caso, a suposição é de que a tarefa se apresente com um grau de dificuldade tal que sozinho, o aluno não poderia dar conta, mas teria êxito com a ajuda de alguém mais competente, seja o professor ou um colega, num processo de interação pessoal e afetiva, que inclui o diálogo, negociação e trocas de experiências (BORUCHOVITCH, 2010b, p. 22).

As diversas metodologias de "transmissão" de informação em uma situação de ensino/aprendizagem apresentam resultados significativos para as pessoas. No entanto, não há construção do conhecimento pedagógico, sem uma atividade mental 
do indivíduo, o qual deve estar com o objetivo de aprender, provocando, assim, um interesse para a atividade desafiadora.

Para que o aluno discrimine a informação relevante da que não é tanto, necessário que os materiais de aprendizagem tenham sido planejados de forma que nem tudo o que se apresenta seja igualmente relevante, que nem tudo seja novo e requeira toda a atenção do aluno [...] (POZO, 2002, p. 149).

Os indivíduos em formação compreendem aquilo que está a ser dito e, mais tarde, serão confrontados com a desagradável surpresa de não conseguirem reproduzir essa mesma informação. Esse fato, ao ser interpretado como falta de capacidades para aprender, poderá conduzir a uma perda de autoconfiança, à frustração e à desmotivação para futuras aprendizagens.

É verdade que, pelo fato de todo o desafio ser difícil, seu enfrentamento encerra o risco de fracasso e de erros. Não se deve passar a mensagem de que é preciso acertar da primeira vez. Muito menos se pode supor que os alunos devam ser poupados de erros e fracassos e que, por isso, as tarefas escolares devem sempre fáceis e divertidas, a serem cumpridas sem nenhum risco (BORUCHOVITCH, 2010b, p. 21).

Para que a prática pedagógica conduza ao sucesso da aprendizagem, faz-se necessário que o nível de dificuldade das atividades propostas deva estar ao alcance de todos. O formador deve garantir a resolução mínima dos exercícios por todos os participantes; as correções necessárias não devem assumir a forma de crítica destrutiva, mas devem ser feitas em forma de sugestão, ou de incentivo ao debate, conduzindo à autodescoberta e à autotransformação; e é muito importante a informação a respeito dos resultados obtidos, a qual significa um reforço positivo, o que reduz a insegurança. "É mais fácil envolver os alunos quando a situação proporciona uma participação mais ativa: as situações de pesquisa são, evidentemente, as mais propícias para arrancar os alunos da passividade, [...] o saber só tem interesse na medida em que mexe com as incertezas [...]" (GALAND; BOURGEOIS, 2011, p. 229).

Existem alguns fatores ou elementos que podem condicionar a aprendizagem que são os internos ao próprio indivíduo, fazendo parte, quer das suas características de personalidade, quer das suas características físicas :

- cognitivos - a percepção, a atenção e a memória;

- socioculturais - a família, os grupos de pertença, a comunidade e a sociedade (valores, representações e estereótipos);

- biológicos - os neurofisiológicos e os genéticos;

- emocionais - que pode ser classificado como "estados de espírito" (Fatores que influenciam a aprendizagem 2012, p. 1) 
Todos esses indicadores são de fundamental relevância para que a aprendizagem aconteça de forma eficaz, alcançando todas as necessidades básicas:

[...] as pessoas não possuem muito controle sobre 0 ambiente físico e social que se impõe; no entanto, podem definir como interpretam e reagem a ele. Na maior parte das vezes, o ambiente é potencialidade, o que exige seleção do que e de como será vivenciado. $\mathrm{O}$ ambiente criado não existe de fato, a priori, suas condições decorrentes da ação pessoal (BORUCHOVITCH, 2010b, p. 127).

A família tem sido lembrada muito mais como local para pedir socorro quando há dificuldades do que como espaço e potencialidade de motivação do estudante. Quando, na escola, as coisas funcionam bem e ocorrem dentro da "normalidade" pouco ou quase nada de espaço é dado à família como agente e colaboradora na aprendizagem dos estudantes. No entanto, quando surge o fracasso, essa tem sido apontada como uma das causas. Os pais parecem interferir na motivação dos filhos, "[...] não só pela imagem que lhes comunica de suas capacidades e do valor das matérias escolares, como também pela maneira como se motivam e motivam seus filhos fora da escola" (GALAND; BOURGEOIS, 2011, p. 60).

Os elementos externos ao próprio indivíduo, que podem facilitar o processo de aprendizagem são (da responsabilidade do formador):

- definir objetivos e dá-los a conhecer;avaliar pré-requisitos;

- explicitar as estratégias;

- compreender o contexto;

- manter o grupo ativo e participante (proporcionar trabalhos de grupo e de investigação);

- utilizar os meios técnicos e práticos disponíveis (vídeo, data - show e outros);

- fazer sínteses parcelares e conclusões;

- desenvolver exercícios práticos;

- realizar a avaliação da aprendizagem;

- discutir os resultados (Fatores que influenciam a aprendizagem, 2012, p. 1).

O educador precisa reconhecer os esforços dos alunos e realçar seus progressos, adotar a visão de normalidade do erro, ou seja, de que faz parte de qualquer aprendizagem errar e que há sempre oportunidade de melhorar seus resultados, assim a aprendizagem:

- deve processar-se num clima de confiança e abertura que propicie a partilha de experiências e vivências, visando um enriquecimento mútuo;

- não deve ser estanque mas negociada, os objetivos devem ser explícitos e partilhados; 
- deve situar-se relativamente a um quadro de referência, apelo às experiências e vivências dos formandos, no sentido de os motivar e implicar;

- deverá ser dirigida para o aqui e agora dos acontecimentos, as finalidades devem ser explícitas. (Fatores que influenciam a aprendizagem, 2012, p. 1).

De acordo com o entendimento de Hannoun (1998), no processo de aprendizagem, portanto, é fato que o mestre pode incentivar, facilitar a participação ativa do aluno. É nisso que consiste, essencialmente, sua arte pedagógica, mas, seja qual for seu talento, "[...] no término de sua ação, ele deve supor que o aluno está motivado para construir, completar ou mesmo corrigir o conteúdo da mensagem escolar, e que a competência assim adquirida se tornará aptidão de sua pessoa" (HANNOUN, 1998, p. 36).

\section{Considerações finais}

A literatura consultada para este estudo buscou autores como Galand, e Bourgeois (2011); Burochovitch (2010); Marchesi (2006); Pozo (2002), dentre outros, os quais tem mostrado que as crenças que o sujeito alimenta de si mesmo e de sua capacidade de aprender e as expectativas que alimentamos das pessoas, também, influenciam o modo como interagimos com essas e o quanto somos capazes de investir ou de desistir de um relacionamento. Na relação pedagógica não é diferente. Estudos realizados com professores mostram que quando o professor alimenta uma expectativa positiva em relação ao estudante, este tem muito mais probabilidade de ser bem-sucedido, valendo o contrário, também, quando o professor não acredita no estudante, $\mathrm{O}$ qual sinaliza isso por meio de seu comportamento, por diferentes atitudes, fazendo-o confirmar o que é esperado desse em termos de melhorar o desempenho, o que reforça a importância do educador saber disso e investir em termos de aprendizagem, evitando condutas ou comportamentos que coloquem em suspeita ou deixem dúvida o que esse pensa de seus estudantes, especialmente quando se tem uma imagem mais depreciativa.

A motivação é um problema pinacular na educação, afeta diretamente o ensino, ou seja, motivar os alunos torna-se uma exigência constante para quem ensina. Hoje, a motivação do professor, do aluno, é uma das questões mais urgentes que temos. Sabemos que essa não pode ser ensinada e nem treinada, mas sim provocada, pois a motivação influencia nos resultados de aprendizagem, bem como na interação social em classe. 
Um dos desafios que os agentes educacionais devem enfrentar é manter os ambientes e as atividades de aprendizagem favoráveis às sinergias das diferentes preocupações dos alunos (autonomia, competência, vinculação, etc.) e minimizar a concorrência entre elas (GALAND; BOURGEOIS, 2011, p. 15).

Para entendermos melhor como funcionam os mecanismos volitivos ou de busca do sujeito por algo, ou seja, o que o motiva, faz-se necessário pensar a partir de duas interrogações que, normalmente, alguém se faz diante de uma decisão de aceitar ou não tal condição ou proposta (seja de aprendizagem escolar ou não): o que isso significa para mim? Em que eu posso usar isso? Estão em jogo as dimensões do sentido e da necessidade. Segundo o pesquisador Albert Ziegler (apud GALAND; BOURGEOIS, 2011), a motivação depende de três fatores: primeiro, os alunos devem sentir-se no "controle". Isso é possível, por exemplo, com uma "negociação" comum dos objetivos do aprendizado; segundo, a competência de cada um deve ser reconhecida e valorizada; e terceiro, é fundamental a ligação social proporcionada pelo aprendizado - por exemplo, por meio de trabalhos em grupo, nos quais se encontra grande parte da dificuldade do trabalho do professor. Estee nem sempre consegue reunir argumentos para demonstrar porque é importante e para que serve, ou o estudante não se envolve por acreditar que não vale a pena despender esforço, não percebe o sentido, nem sequer dá ouvidos ao professor, desiste antes mesmo que a proposta lhe seja exposta. A decisão de não fazer ou de se empenhar vem antes da construção dos argumentos do professor para saber o que e como aquela atividade pode lhe ser útil ou significativa.

O professor não pode apostar nas crenças negativas e errôneas que ainda são alimentadas, por parte de alguns, a respeito da motivação e sua forte relação com a aprendizagem, e com pensamentos de que já faz sua parte em ensinar. Se o aluno quiser, ou não, aprender é ele quem deve se esforçar e decidir. Faz-se necessário acreditar e entender que o professor tem papel ativo em mobilizar o estudante. A motivação é de extrema e fundamental importância e está muito relacionada à boa aprendizagem, o que demonstra a necessidade de levar em consideração todos os fatores motivacionais relacionados. 


\section{Learning and motivational factors related}

\section{Abstract}

This text is a qualitative bibliographic research, resulting from a work Graduation, for which was used as a basic source books and articles of renowned authors and aims to demonstrate the importance of motivation in school environment, how it helps, interfere with educational processes in the school environment, in the acquisition of knowledge, in short, in the work of the teacher, in teaching and learning. The architecture of the text is structured to conceptualize motivation and learning and then relates them to the interfering motivational factors in learning and improving the quality of education. Concludes by demonstrating that the applicant's motivation speech in school spaces, however, with a long way to go in regards to form themselves into objective actions for its incorporation into pedagogical practice. What is evidenced is revealing attitudes of lack of motivation for learning and the school work. The educators have elementary notion about their importance in the educational process, but they lack deeper knowledge of how to insert it into their daily practice; to use of motivational factors to improve relationships with students and their acquisition of knowledge.

Keywords: Motivation. Learning. Teacher. Student.

\section{Notas}

1 Denomina-se de curva de aprendizagem a representação gráfica, do nível médio cognitivo, atingido em determinada atividade realizada ou ferramenta utilizada. No início, o aumento da retenção de informações é mais agudo, gradualmente equilibra-se, o que significa que cada vez menos informação nova é retida após cada repetição. Pode demonstrar também a dificuldade inicial de aprender algo e, em certa medida, o quanto se pode aprender após a familiaridade inicial.

2 Neste texto não temos a pretensão e nem o fôlego suficiente para esgotá-los, o que pretendemos é demarcar sua existência e abordar aspectos relacionados à esses que estejam atrelados à motivação que leva à aprendizagem.

3 As crenças do professor influenciam e incitam o estudante, pouco importa se essas são verdadeiras ou falsas. Estudos de laboratório demonstraram que os professores que acreditavam interagir com indivíduos motivados intrinsecamente, adotaram um estilo favorável à autonomia entre os alunos, enquanto que os professores que acreditavam interagir com um aluno motivado extrinsecamente adotaram comportamentos interpessoais mais controladores (GALAND; BOURGEOIS, 2011). Esse exemplo demonstra a força de orientação que tem as crenças das pessoas.

\section{Referências}

BÖCK, Vivien Rose. Motivação para aprender e motivação para ensinar. Porto Alegre: CAPE, 2008.

BUROCHOVITCH, Evely (Org.). Aprendizagem: processos psicológicos e o contexto social na escola. Petrópolis: Vozes, 2010.

Motivações para aprender: aplicações no contexto educativo. Petrópolis: Vozes, 2010b. 
2004.

Aprendizagem: processos psicológicos e o contexto social na escola Petrópolis: Vozes,

BZUNECK, José A. Como motivar os alunos: sugestões práticas. In: Motivações para aprender: aplicações no contexto educativo. Petrópolis: Vozes, 2010.

COSTA, Marisa (Org.). A escola tem futuro? Rio de Janeiro: DP\&A, 2003.

FATORES que influenciam a aprendizagem. Disponível em: <http:/ formacao.fikaki.com/manual/teorias-factores-aprendizagem/processos-etapas/fatores>. Acesso em: 27 nov. 2012.

GALAND, Benoit; BOURGEOIS, E. (Orgs.). Motivar-se para aprender. São Paulo: Cortez, 2011.

GUIMARÃES, Valter S. Formação de professores: saberes, identidade e profissão. Campinas-SP: Papirus, 2004.

HANNOUN, Hubert. Educação: certezas e apostas. São Paulo: UNESP, 1998.

HOUAISS, Antonio. Dicionário Houaiss da Língua Portuguesa. Rio de Janeiro: Objetiva, 2001.

ILLERIS, K. Uma compreensão abrangente sobre a aprendizagem. In: Teorias contemporâneas da aprendizagem. Porto Alegre: Penso, 2013.

JARVIS, Peter. Aprendendo a ser uma pessoa na sociedade. Aprendendo a ser eu. In: ILLERIS, K. (Org.). Teorias contemporâneas da aprendizagem. Porto Alegre: Penso, 2013.

MARCHESI, Álvaro. O que será de nós, os maus alunos? Porto Alegre: Artmed, 2006.

MEIRIEU, Philippe. O cotidiano da escola e da sala de aula: o fazer e o compreender. Porto Alegre: Artmed, 2005.

PORTILHO, Evelise. Como se aprende? Estratégias, estilos e metacognição. Rio de Janeiro: Wak, 2009.

POZO, Juan Ignacio. Aprendizes e mestres: a nova cultura da a aprendizagem. Porto Alegre: Artmed, 2002.

RAY, Fernando L. G. O sujeito que aprende: desafios do desenvolvimento do tema da aprendizagem na psicologia e na prática pedagógica. In: TACCA, Maria C. (Org.). Aprendizagem e trabalho pedagógico. Campinas-SP: Alínea, 2008.

RESENDE, Lúcia M. G. de Paradigma e trabalho pedagógico: construindo a unidade teórico-prática. In: TACCA, Maria C. (Org.). Aprendizagem e trabalho pedagógico. Campinas-SP: Alínea, 2008. 